\title{
EMPLOYEE STRESS REACTIONS TO A MUNICIPAL GOVERNMENT STRIKE
}

\author{
CHRISTINE M. WICKENS \\ York University, Toronto, Canada
}

\begin{abstract}
In 2002, a large municipality in southern Ontario (Canada) experienced a sixteen-day strike, resulting in the shutdown of all municipal services. To determine the psychological impact of the strike on the employees, questionnaires were distributed to a sample of employees before, immediately following, and four months after the labor dispute. Results identified financial concern and cynicism toward the city and the union as predictors of employee anger immediately following the strike. Financial concern, city cynicism, and adaptiveness were identified as predictors of employee mood. Only financial concern and - to a lesser extent, anger and cynicism toward the union-declined following the conclusion of the strike. Implications of the results and recommendations for future research are discussed.
\end{abstract}

Labor disputes, strikes, and lockouts have become commonplace in the world's free market economies. They affect thousands of employees in both private and public sectors each year. Media coverage of lengthy labor disputes has often addressed the impact of these conflicts on employees and their families, citing repercussions such as marital breakdown and increased personal violence, e.g., $[1,2]$. Much of the academic literature in the field has focused on the decisionmaking processes of management and employees in labor disputes, e.g., [3, 4], as well as the political, economic, and industrial implications of these job actions, e.g., [5-7]. Surprisingly few studies have examined the psychological impact of labor disputes on the employees involved.

(c) 2007, Baywood Publishing Co., Inc. doi: 10.2190/CN.31.2.b

http://baywood.com 


\section{STRESS RESPONSES}

\section{Transactional Model of Stress}

Although not cited by the few researchers who have assessed the psychological impact of strikes on employees, Lazarus and Folkman's transactional model of stress can help researchers understand these effects [8]. According to this model, psychological stress is the result of perceiving environmental demands as taxing or exceeding personal resources. Stress can be defined as the cognitive, emotional, physiological, and behavioral responses to this perception. The cognitive appraisal of events is a major determinant of the level of stress response and is influenced by the dynamic interactions between situation- and person-related variables. Figure 1 contains a hypothesized transactional model of strike-related stress, adapted from Lazarus and Folkman's original model [8]. When viewed from the perspective of the transactional model of stress, the majority of existing research has examined a variety of stress responses to labor disputes (see [9]), and the various situation- and person-related factors that moderate these responses (e.g., existing work stressors, level of financial savings, attitude toward unions, social support, etc.). Other studies have examined the impact of strikes on labormanagement relations and job satisfaction.

\section{Stress Responses to Labor Disputes}

In terms of the various stress responses to labor disputes, a few studies have provided some insight. Although based on a very diverse set of labor disputes among a variety of occupations (e.g., airline pilots and engineers [10-12]; college teachers [13]; and staff in a maximum security hospital for the criminally insane [14]), the reported impact of each of these labor disputes on workers' physical, emotional, and psychological health has followed a very similar pattern.

Employees experienced elevated distress, including heightened anxiety and tension. This distress contributed to a variety of psychological responses, including anger and hostility, paranoia, obsessive-compulsive behaviors, depression, and disturbances in sleeping and dreaming. Physically, employees reported deterioration in their general health, as well as flare-ups in physical symptoms, such as higher blood pressure, nausea, and loss of appetite. Their distress also contributed to changes in alcohol consumption and smoking habits. Interpersonally, stress related to the labor dispute was often associated with a strained family life, impaired marital relationships, and a general distrust of company management. In some cases, where the research was longitudinal in nature, stress associated with the labor dispute persisted for six [13] to twelve months [11] following the resolution of the conflict.

Adding to this list of stress responses to labor disputes, Bluen and Barling cited acts of violence against people and property, continued hostility between labor and management resulting in reduced productivity and sabotage, and 


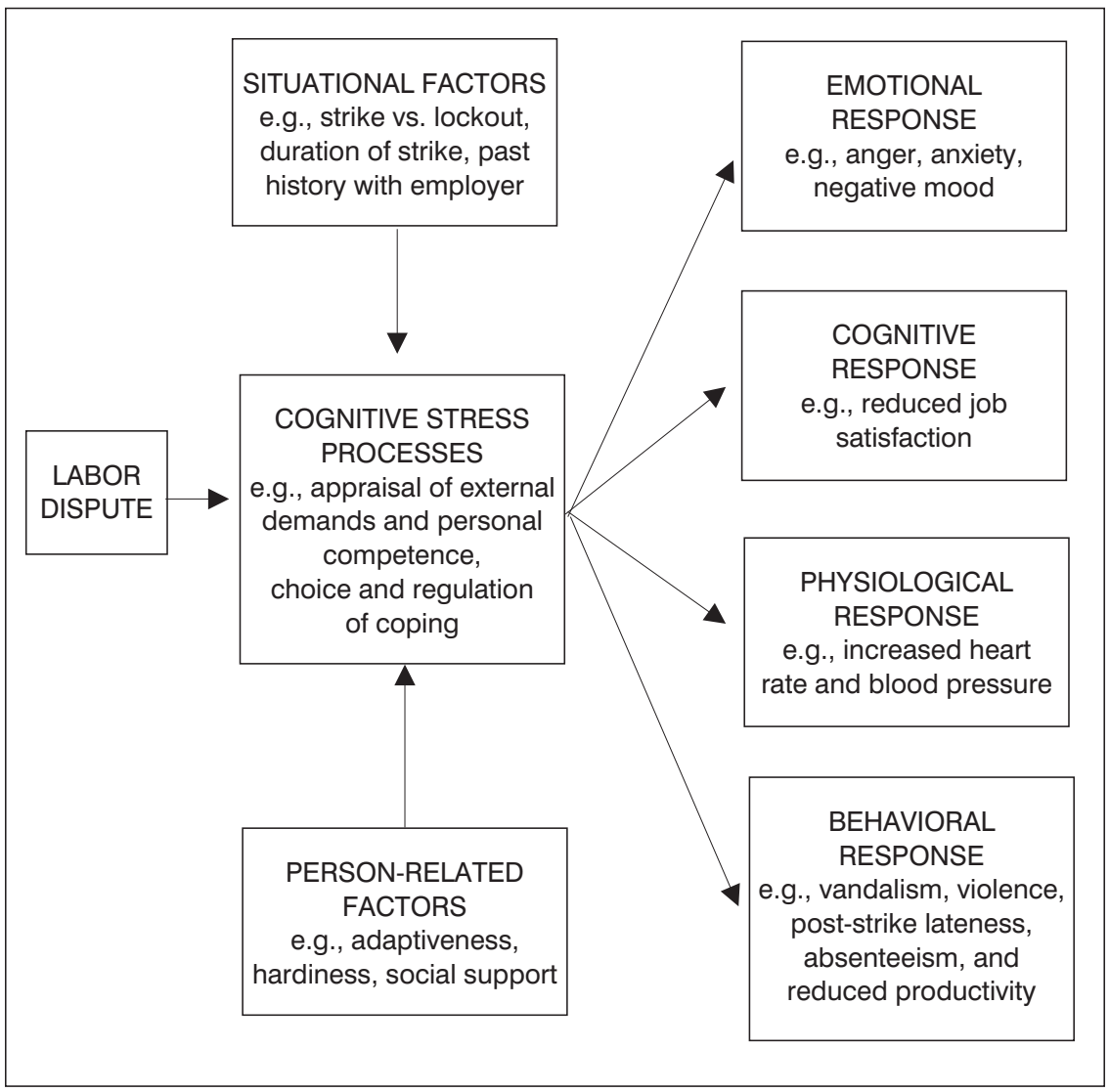

Figure 1. Transactional model of strike-related stress (adapted from [8]).

negative consequences for families and communities due to loss of income [9]. In trying to explain these stress responses, Barling and Milligan concluded that these symptoms could have been the result of several processes, including a) major role changes (i.e., going from being employed white-collar workers to being picketers); b) the lack of time structuring associated with unemployment, which can lead to boredom and depression; and c) the feeling of powerlessness during a strike, which may significantly affect one's ability to cope [13].

\section{Situation- and Person-Related Factors}

Although the list of potential situation- and person-related factors that can influence the stress response to labor disputes is virtually endless, only a limited 
few of these variables have been empirically assessed. Bluen and Jubiler-Lurie examined the role of social support from family and work colleagues on the changes in psychological well-being resulting from labor negotiations [15]. Industrial relations stress associated with negotiations was found to contribute to psychological distress, even three months after completion of the negotiations. Family support exerted both direct and indirect effects on psychological well-being. Regardless of the level of industrial relations stress experienced, low family support was associated with poorer psychological well-being than high family support. Support from work colleagues had no main or moderating effects on psychological well-being, but did predict changes in job satisfaction.

Bluen and Edelstein examined the role of emotional support offered by a trade union on the psychological distress experienced by employees four months after a serious industrial accident [16]. Union emotional support buffered the impact of the disaster, lowering psychological distress levels of surviving workers. Likewise, Barling, Bluen, and Fain examined the role of family and supervisory support following a tragic industrial disaster [17]. As in the study by Bluen and Jubiler-Lurie [15], family support was associated with psychological distress and marital functioning, whereas supervisory support was associated with job satisfaction [17]. Together, these findings underline the importance of congruence between the source of social support and the nature of the stressor.

Other studies have identified a variety of individual difference factors that have influenced employee reaction to industrial conflict. Burke examined the conflict between medical practitioners and the government of Canada, a battle that has raged since the introduction of universal government health insurance in the 1960s $[18,19]$. According to Burke, questionnaire data revealed that demographic variables, characteristics of one's medical practice, work stressors, and satisfaction with work and professional practice were all significant and independent predictors of physician militancy. Stoner and Arora assessed predictors of the psychological health of employees in the seventh week of a seven-month strike from a large multinational manufacturer of industrial equipment [20]. The researchers found that a greater level of financial savings, involvement in more recreational activities, a greater perception of social support, favorable attitudes toward the union, and a shorter expected duration of the strike helped to sustain the psychological health of strikers [20].

Although each of these studies has identified several psychosocial consequences of labor disputes for employees, as well as situation- and person-related factors that affect these stress responses, our understanding of the relationships among and the impact of these variables is still highly limited. Labor disputes are a highly complicated phenomenon, involving sociocultural and economic-institutional forces, as well as interpersonal and intrapsychic dimensions 
[21]. Given these complexities, it is important that studies examining labor disputes include field research. Although laboratory studies can provide valuable insight, they are not always able to simulate the intricate and subtle real-world variables that may significantly influence striking employees [22, 23]. Unfortunately, psychosocial researchers normally face limited access during a labor dispute [9]. For this reason, it is important that researchers take every available real-world opportunity to further our understanding of strike-related phenomena.

To date, we have examined only a few of the variables that may play a role in the transactional model of strike-related stress. It is equally imperative to study every available labor dispute because they are each so unique. As Nicholson and Kelly pointed out,

$[\mathrm{O}]$ nly the most superficial and trivial facets of strikes unite them under a single heading, i.e., being a stoppage of work enacted by a group of employees. . . They vary in terms of their degree of organization or informality, the issues latent or manifest in the dispute, the variety and clarity of the demands being made, the relevance of official machineries and procedures, the scale of time and manpower involved, and the history of relations preceding the event [21, p. 276].

Although no grand equation will ever be able to predict the specific events that occur during a strike, psychosocial researchers can help to identify, and to reduce or avoid, the more harmful consequences that these many diverse types of job actions may produce. In accordance with the many appeals for further field research, the current pilot study was a real-world research endeavor to replicate and extend findings concerning the impact of labor disputes on employees and the variables that play a role in this process.

In the summer of 2002, a large municipality in southern Ontario experienced a sixteen-day strike, resulting in a shutdown of all municipal services, including garbage collection, summer camp programs, and issuance of building and zoning permits. The impact on the community was extreme, creating a significant amount of pressure on both the municipality and the union to settle. The current study involved three phases of questionnaire distribution. The first set of questionnaires was distributed in the week prior to the strike; the second set was distributed in the four weeks immediately following the strike; and the third set of questionnaires was given out in the fourth month following the strike. Each phase of the research involved an assessment of employee anger, general mood, financial concern, adaptive coping ability, and cynicism toward the city and the union.

\section{PREDICTIONS}

Based on the transactional model of stress, each of the variables included in the study could be considered responses to the strike or predictors of those 
stress responses. However, given the limitations of a pilot study, an assessment of all possible relationships between variables could not be performed. Therefore, based on the findings of previous research, each of the variables was assigned either a predictor or an outcome role for the current study.

Anger and general mood were selected as the stress response variables. Previous research has found that negative industrial relations events (e.g., discrimination or biased treatment, conflict with supervisors or co-workers, and strikes) can increase levels of anger and hostility and can negatively influence mood $[10,11,24]$. The remaining variables in the current study were expected to predict the level of participants' general mood and anger.

Adaptiveness is the ability to adapt and adopt coping techniques appropriate for a given situation. It combines three characteristics: a) judgment, meaning the ability to discriminate between controllable situations necessitating active coping and uncontrollable ones that are better handled passively, b) determination, needed to overcome obstacles arising in situations judged controllable, and c) self-control, needed to react passively in provocative situations judged uncontrollable [25]. Adaptive coping ability was conceptualized as a person-factor in the transactional model of stress and was expected to reduce employee anger and improve general mood. However, previous research involving similar factors has been inconsistent.

Social support, a similar but situational factor, has been found to assist employees in coping with strike-related stresses, but has been effective only when there is congruence between the type of stressor and the type of social support $[15,26]$. It is possible that adaptiveness is a more general or allencompassing construct that does not require the same level of domain-specificity to be effective. However, a similarly comprehensive personality construct, known as hardiness, has also produced mixed results. Although some findings have suggested that hardiness reduces the negative consequences of organizational stress, others have indicated that it can exacerbate psychological distress [15]. According to Bluen and Barling, personality and social support may fulfill different buffering functions [9]. With a stable and dispositional nature, personality resources may be more appropriate for acute and sudden-impact stressors, such as strikes. Social support may be more relevant for chronic stressors given that it may take time to seek and receive the benefits of social support. Given the degree of inconsistency in past research, it was hoped that the inclusion of the adaptiveness variable would provide valuable insight; however, this same inconsistency made predictions regarding adaptiveness difficult. Beyond the expectation that adaptiveness would predict and improve anger and general mood, no specific hypotheses concerning the association of adaptiveness with the other predictors were postulated.

The threat or experience of financial difficulty resulting from being out of work during a labor dispute can be a source of great distress. Stoner and Arora found that the level of monetary savings had a direct effect on the psychological 
health of striking employees [20]. Level of savings also had a direct effect on the passive recreational activities of strikers (e.g., going to movies, concerts, night clubs, etc.), which further affected their psychological health. Vispo and Shine's interviews with striking employees found that financial stresses were very common, and led to additional interpersonal problems [14]. In cases where an employee's marriage was already shaky, financial difficulties resulting from the strike were identified as significant contributors to a divorce or separation. In the current study, financial concern was expected to increase the experience of anger and to worsen general mood. No specific hypotheses concerning the association of financial concern with cynicism toward the city or the union were put forward.

Although one might expect that attitudes toward the employer and the union might be opposite ends of the same continuum, that is not necessarily the case. Several studies have suggested that dual allegiance to union and company management is possible, e.g., [27, 28]. In fact, Fullagar and Barling demonstrated that union and company commitment do not often share common predictors [29]. Few studies, however, have examined the impact of a labor dispute on cynicism toward the employer or the union, and there is little information on the role that cynicism may play in other employee reactions. Stagner and Eflal distributed questionnaires to unionized employees from the automobile manufacturing industry before and during a 1976 strike, after the settlement of a national contract, and seven months after the strike had ended [23]. As one might expect, there was increased hostility toward the employer during the strike. Union leaders acquired additional prestige and influence over members during the dispute, but their overvaluation vanished in the months that followed. Other studies have found a lower level of job satisfaction in the post-strike period $[14,24]$, which may reflect a form of cynicism toward the employer $[29,30]$, and may lead to increased commitment to the union [31]. Despite these indications that cynicism toward the employer may worsen before and after a strike, and that cynicism toward the union may decline temporarily during a strike, it must be noted that there is normally a moderate correlation between anger and cynicism [32]. These two concepts are often considered to be the affective and cognitive components of a single construct. Therefore, it might be argued that both cynicism toward the city and toward the union in the current labor conflict would be expected to contribute to a greater level of employee anger and a more negative employee mood.

In terms of changes in the measured constructs over the course of the strike, few hypotheses could be made, given that no one knew how long the strike would last. Based on the findings of Stagner and Eflal [23], it might be argued that city cynicism should be high and union cynicism should be low before and immediately following the strike. However, it is possible that the duration of the strike assessed by Stagner and Eflal influenced their findings. Therefore, the 
current study made no specific predictions regarding the longitudinal analysis of the measured constructs.

\section{METHOD}

\section{Participants}

Questionnaires were distributed to a snowball sample ${ }^{1}$ of participants from the Works Department and the Parks and Recreation Department. Snowball recruitment was the only available option given the looming strike deadline at the time of the study; however, the fact that participant recruitment was initiated in multiple departments of the city government, as well as multiple locations within those departments, should have helped minimize problems of nonrepresentativeness that are associated with nonrandom sampling. A total of thirty-six employees agreed to take part in the first phase of the study, producing a response rate of 55 percent of all employees asked to participate. Of these employees, twenty-six also responded to the second questionnaire, along with eighteen additional subjects who had not taken part in the study prior to the strike. In the third phase of data collection, an attempt was made to contact all forty-four participants involved in the second phase of the research. A total of thirty-five of these participants were contacted and responded to the final questionnaire. Twenty-five employees participated in all three phases of the study. Participants were guaranteed that responses to all questionnaires would be completely confidential.

\section{Measures}

Questionnaires were designed to assess emotional and attitudinal reactions to the strike and the role of employees' coping techniques in moderating these reactions. The questionnaires included measures of anger, general mood, adaptive coping, levels of financial concern resulting from the strike, and cynicism toward both the city and the union. These measures were identical for all three phases of the study, except that verb tense varied in some items and instructions depending on whether the strike was pending or had passed at the time of survey completion. As well, adaptive coping, measured using the Personal Functioning Inventory (PFI), was completed by participants only once, either in phase 1 before the strike or in phase 2 immediately following the strike. An analysis of variance (ANOVA) revealed no significant difference in levels of adaptiveness between participants who completed the measure in phase 1 versus phase 2 . In addition, demographics and the nature of participants' employment positions were also assessed.

\footnotetext{
${ }^{1}$ Snowball sampling is a form of purposive sampling. Members of a particular subgroup within a population are asked to participate in a study and to identify other members of the subgroup who might also be willing to participate. This sampling method can be beneficial when doing certain types of field studies or when trying to identify members of a select or otherwise inaccessible population.
} 
Anger

Spielberger's State-Anger Scale was used to assess employees' anger levels [33]. This measure includes ten items that tap feelings of anger at a given moment in time. Participants were asked to indicate how they had felt in the previous week concerning the potential city strike/lockout or the recent city strike. Participants responded on a five-point scale ranging from $1=$ not at all to $5=$ very much so. The scale included items such as "I am mad," "I feel like yelling at somebody," and "I feel like banging on the table." Responses to the ten items were averaged to produce an anger score. At least eight of the ten items had to be answered for a score to be calculated.

\section{General Mood}

Employees' general mood levels were assessed using Mackay, Cox, Burrows, and Lazzerini's Stress Arousal Checklist [34]. This measure consists of five positive mood items (relaxed, contented, peaceful, comfortable, and calm), and five negative mood items (tense, bothered, nervous, uneasy, and distressed). On a scale ranging from $1=$ not at all to $5=$ extremely, participants were asked to indicate the extent to which they had generally felt this way in the past week. The positive items were reverse coded, and responses to the total ten items averaged to generate a participant's general mood score. Higher scores indicated a more negative mood. At least eight of the ten items had to be answered for a score to be calculated.

\section{Adaptiveness}

Also included in the questionnaire was the Personal Functioning Inventory (PFI) developed by Kohn et al. [25]. The PFI measures the concept of adaptiveness, that is, the ability to determine and utilize coping techniques appropriate for a given situation. The PFI includes thirty items; half of which are adaptive principles of coping (e.g., "I've learned not to get down on myself for minor mistakes I make"), and half of which are maladaptive principles of coping (e.g., "When my rights are threatened, I get too upset to act in the most effective way"). Participants were asked to indicate their level of agreement with each statement on a five-point scale ranging from $1=$ strongly disagree to $5=$ strongly agree. The maladaptive items were reverse coded, and responses to the thirty items averaged to produce each participant's adaptiveness score. Higher scores indicated a more adaptive style of coping. At least twenty-eight items had to be answered for a participant's mean score to be calculated.

\section{Financial Concern}

The extent to which employees worried about the financial implications of the labor dispute was measured using five items developed specifically for the 
current study. Participants were asked to indicate their level of agreement with each item, ranging from $1=$ strongly disagree to $5=$ strongly agree. Two negatively valenced items were reverse coded, and the total five items averaged to produce a financial concern score. Four of the five potential responses were needed for a mean score to be calculated. The five financial concern items were distributed randomly among the city and union cynicism items described below.

\section{City and Union Cynicism}

The final psychological construct assessed in the current study was cynicism directed toward the city and toward the union. Eaton's occupational cynicism scale [35] was altered so that it could be used with the municipal government sample. The original measure consisted of fifteen items, including five items for each of its three subscales of cognition, affect, and behavior. According to Eaton, the cognition and affect subscales, and the overall cynicism measure, have demonstrated strong internal consistency $(\alpha>.86)$ [35]. However, the behavior subscale has achieved only moderate internal reliability $(\alpha=.65)$ [35]. For the current study, the cognition and affect items were altered so that they were specifically directed toward either the city or the union. The behavior items in the original measure could not be applied to the municipal government context. Therefore, five new items probing behavioral expressions of cynicism toward the city and five new items probing behavioral expressions of cynicism toward the union were developed for use in the current study. For all items, respondents were asked to indicate their level of agreement on a scale ranging from $1=$ strongly disagree to $5=$ strongly agree. Items worded in favor of either the city or the union were reverse-coded, and appropriate items averaged to produce composite cynicism scores. At least four items for the subscales and twelve items for the overall cynicism scale needed to be answered for mean scores to be calculated.

\section{RESULTS}

The statistical analysis in the current study involved an examination of the relationships between various psychological constructs immediately following the strike (phase 2), since that was the most crucial phase of the study. Specifically, adaptiveness, financial concern, and city and union cynicism were regressed onto the stress responses of anger and general mood. The analysis also involved a review of changes in these constructs over the three phases of the labor dispute.

\section{Demographics}

\section{Participants Involved in Phase 2}

Of the forty-four participants involved in phase 2 of the current study, twentyone were male and twenty-three were female. The mean age of participants was 25.29 years $(S D=9.55)$. Ten respondents were full-time employees of the city, 
whereas thirty-four were part-time employees. The average number of hours worked per week, however, was $32.21(S D=13.11)$, which suggests that most of the part-time employees were working a full work-week. An ANOVA comparing full- and part-time employees on the six composite variables of anger, stress, financial concern, adaptiveness, and city and union cynicism produced no significant results. Collectively, participants had been employees of the city for 6.66 years $(S D=5.81)$.

Participants Involved in Phases 1, 2, and 3

Of the twenty-five employees who participated in all three phases of the study, eleven were male and fourteen were female. The mean age of these participants was 26.29 years $(S D=9.57)$. Five respondents were full-time employees of the city, whereas twenty were part-time employees. The average number of hours worked per week was $28.76(S D=12.47)$, again suggesting that most of the part-time respondents were working close to a full work-week. As with the other sample, the difference in cell sizes was ignored, and an ANOVA comparing full- and part-time employees was conducted. Although financial concern appeared greater among part-time employees $(M=3.88, S D=0.83)$ than full-time employees $(M=2.92, S D=0.95)$, the $F$-test failed to achieve a level of significance that used a Bonferroni adjustment to control for Type I error $(F(1,23)=5.02, p=.04)$. Overall, participants had been employed by the city for an average of 7.22 years $(S D=4.95)$.

\section{Gender Differences}

For both groups of samples, gender differences were assessed among the six primary variables of interest (anger, general mood, financial concern, adaptiveness, and city and union cynicism). For the sample of participants involved in phase 2 of the study, general mood was the only variable to exhibit a significant gender difference $(F(1,42)=8.15, p=.007)$, such that females $(M=3.03, S D=0.90)$ reported significantly more negative moods than did males $(M=2.35, S D=0.67)$. For those participants involved in all three phases of the pilot research, no significant gender differences were found.

\section{Psychosocial Consequences Immediately Following the Strike}

Means, standard deviations, Cronbach alphas, and intercorrelations of the variables assessed for this study are shown in Table 1. With the exception of the behavior subscale of both cynicism measures, all reliabilities ranged from .67 to .95 . Since the behavior subscales produced inadequate internal reliability $(\alpha \leq .51)$, both city and union cynicism were calculated using the cognition and 


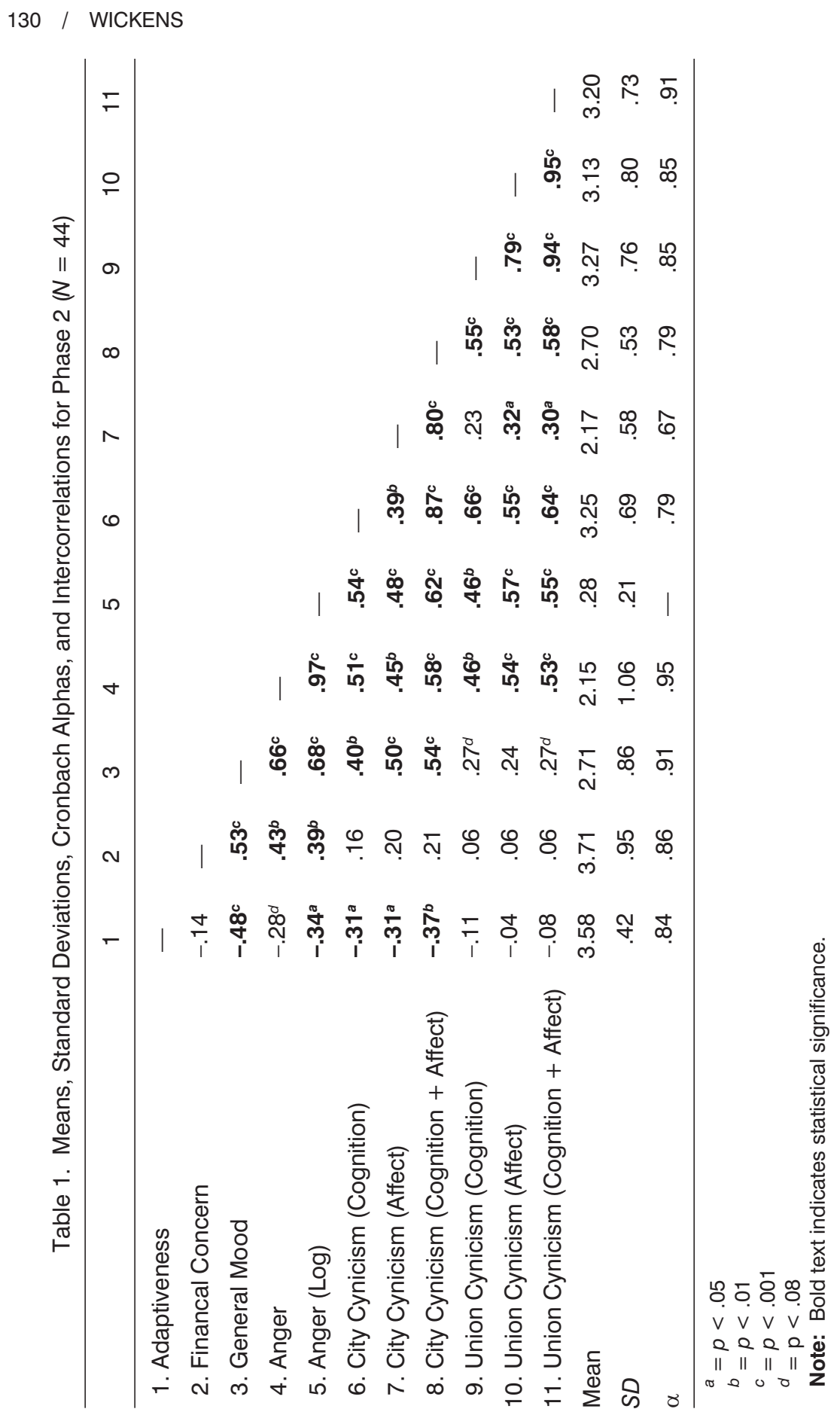


affect subscales only. As well, the anger variable achieved significance in a test for skewness (see [36]). To alleviate positive skew, a logarithmic transformation was performed (see Table 1).

When examining the correlation matrix, it can be seen that adaptiveness, as measured by the PFI, was negatively correlated with general mood, log anger, and city cynicism. Financial concern was positively correlated with general mood and log anger. More negative mood levels were associated with higher levels of log anger and city cynicism, and marginally associated with higher levels of union cynicism $(p=.08)$. Greater log anger was related to city and union cynicism, and union and city cynicism were positively related to each other. Scatterplots graphing the bivariate relationships between these variables confirmed that the reported correlations applied for the full range of scores.

To assess predictors of both log anger and general mood, separate standard linear regressions were computed for each of these stress responses. The final regression model for log anger appears in Table 2. As predicted, financial concern and cynicism toward the city and the union made significant positive contributions to log anger. Despite being negatively correlated, adaptiveness failed to predict log anger. Collectively, the predictors for the final model of log anger accounted for 58 percent of the variance. The final regression model for general mood appears in Table 3. As hypothesized, lower levels of adaptiveness, and higher levels of city cynicism and financial concern predicted more negative moods among striking employees. Union cynicism failed to predict general mood. Collectively, the predictors for the final model of general mood accounted for 50 percent of the variance.

\section{Changes in Psychosocial Consequences Over the Course of the Strike}

To examine changes in psychosocial circumstances over the course of the strike, the responses of the twenty-five employees who participated in all three

Table 2. Predictors of Log Anger for Phase 2

\begin{tabular}{llrrc}
\hline Criterion & Predictor & $b$ & $T$ & Significance \\
\hline \multirow{2}{*}{ Log Anger } & Adaptiveness & -.072 & -1.324 & .193 \\
& City Cynicism & .132 & 2.528 & .016 \\
& Union Cynicism & .103 & 3.016 & .005 \\
& Financial Concern & .064 & 2.904 & .006 \\
& Intercept & -.372 & -1.396 & \\
\hline
\end{tabular}

$R^{2}=.58, F(4,38)=15.42, p<.001$ 
Table 3. Predictors of General Mood for Phase 2

\begin{tabular}{llrrc}
\hline Criterion & Predictor & \multicolumn{1}{c}{$b$} & \multicolumn{1}{c}{$T$} & Significance \\
\hline General Mood & Adaptiveness & -.619 & -2.453 & .019 \\
& City Cynicism & .522 & 2.158 & .037 \\
& Union Cynicism & .053 & .335 & .740 \\
& Financial Concern & .381 & 3.734 & .001 \\
& Intercept & 1.936 & 1.563 & \\
\hline
\end{tabular}

$R^{2}=.50, F(4,38)=11.31, p<.001$

phases of the study were subjected to a series of one-way repeated-measure ANOVAs. Included as dependent variables were financial concern, log anger, ${ }^{2}$ general mood, and city and union cynicism. Although a cross-lagged regression analysis might have been preferable here, the extremely small number of participants prevented the use of this preferred statistical technique. The Bonferroni adjustment used to control Type I error in the ANOVAs dictated a minimum level of significance of .01. Only financial concern produced a significant result $(F(2,48)=6.34, p=.004)$. Subsequent multiple pairwise comparisons, using a minimum significance level of .017 to control for Type I error, revealed that there was a significant difference between phases 1 and $2(t(24)=3.61, p=.001)$, and a marginally significant difference between phases 1 and $3(t(24)=2.52, p=.019)$. Also, although union cynicism failed to meet the significance requirement of the Bonferroni adjustment, it also appeared to differ across the three phases of the study $(F(2,48)=4.10, p=.023)$. Subsequent pairwise comparisons revealed a significant difference between phases 1 and $3(t(24)=2.75, p=.011)$. To a lesser extent, log anger also appeared to differ across the three phases of the study, but again failed to meet statistical significance $(F(2,48)=2.80, p=.071)$. Table 4 contains the means, standard deviations, and Cronbach alphas for each of the variables in each phase of the research.

\section{DISCUSSION}

When examining the means of the various emotional and attitudinal measures, it is clear that on the average employees were not reacting extremely negatively toward the labor dispute. The sample did not express extreme anger, unusually

\footnotetext{
${ }^{2}$ To assess changes in anger across the three phases of study, a log transformation of the anger construct was necessary to resolve excessive skew. Although this transformation was successful for the distribution of anger in phases 1 and 2, log anger in phase 3 continued to suffer from minor nonnormality; however, its effects on the results of the ANOVA should be minimal.
} 
Table 4. Means, Standard Deviations, and Cronbach Alphas

for Phases 1, 2, and $3(N=25)$

\begin{tabular}{|c|c|c|c|c|}
\hline & & Phase 1 & Phase 2 & Phase 3 \\
\hline \multirow[t]{3}{*}{ Anger } & Mean & 1.96 & 2.13 & 1.67 \\
\hline & $S D$ & 1.00 & 1.10 & .80 \\
\hline & $\alpha$ & .95 & .95 & .96 \\
\hline \multirow[t]{2}{*}{ Log Anger } & Mean & .24 & .28 & .18 \\
\hline & $S D$ & .21 & .21 & .18 \\
\hline \multirow[t]{3}{*}{ General Mood } & Mean & 2.83 & 2.77 & 2.67 \\
\hline & SD & .88 & .97 & .87 \\
\hline & $\alpha$ & .90 & .93 & .92 \\
\hline \multirow[t]{3}{*}{ Financial Concern } & Mean & 4.11 & 3.69 & 3.72 \\
\hline & $S D$ & .72 & .93 & .95 \\
\hline & $\alpha$ & .89 & .88 & .90 \\
\hline \multirow[t]{3}{*}{ City Cynicism } & Mean & 2.67 & 2.67 & 2.62 \\
\hline & $S D$ & .54 & .57 & .65 \\
\hline & $\alpha$ & .77 & .85 & .88 \\
\hline \multirow[t]{3}{*}{ Union Cynicism } & Mean & 3.30 & 3.16 & 3.04 \\
\hline & $S D$ & .57 & .80 & .68 \\
\hline & $\alpha$ & .88 & .95 & .94 \\
\hline
\end{tabular}

negative mood, or intense cynicism toward the city or the union, but expressed milder reactions. This may be due to the fact that these reactions were not measured during the job action, or the fact that the strike lasted only sixteen days, a briefer period compared to previous job actions in this municipal government, and in other organizations. Nonetheless, the variation in these emotional and attitudinal measures followed the hypothesized pattern, which was guided by the transactional model of stress.

Most of the correlations among the variables of interest were quite high, and always in the expected direction; however, the results of the regression analyses were mixed. Greater levels of adaptiveness, for instance, were found to predict more negative mood levels, but failed to predict higher levels of anger. By taking a closer look at research focusing on the psychology of emotions, this finding does make sense. Anger is a primary emotion that can lead to the activation of a variety of other feelings, including tension, sadness, and contempt [37]. The positive correlation in the current study between anger and negative mood 
provides some support for this claim. Perhaps the feelings that are activated by anger persist longer and at a more moderate level than the initial anger itself.

Milder and more enduring emotions are termed "moods" and, despite their reduced intensity, they can still affect one's physical and mental well-being [37]. If adaptiveness serves as a buffering function between anger and its associated emotions, it is possible that strikers' levels of adaptiveness did not determine whether they experienced anger, but did have an impact on how that emotion affected their longer-term mood responses. The same theory could explain why adaptiveness was not correlated with financial concern. Although employees' adaptiveness did not determine whether they experienced financial hardship, it may have affected their responses to that stressor. Further research examining these possible moderating effects should be considered. As well, the fact that adaptiveness may help to improve general mood suggests that programs focusing on teaching adaptive coping techniques could be beneficial for employees in future labor disputes, or when handling everyday work stresses.

The results concerning city and union cynicism were also mixed. Although cynicism toward the city predicted both employees' anger levels and negative moods, union cynicism only predicted their anger levels. Although not measured in the current study, perhaps the duration of each form of cynicism explains this finding. Presumably, cynicism toward the city is a more common and frequent form of cognition; employees may be reminded about the perceived reasons for their city cynicism each day that they arrive at work. On the contrary, cynicism toward the union may be less common; employees likely do not interact with their union representatives, or encounter union issues on an everyday basis. Therefore, although the less enduring and more momentary union cynicism may be a source of short-lived anger, it may not affect general mood, which may be a more long-term stress response. It is also possible that the difference in duration of each form of cynicism explains the fact that adaptiveness was negatively correlated with city cynicism but not correlated with union cynicism. Perhaps the coping skills used by adaptive individuals are more effective over the long-term, so that the more enduring city-related stressors benefit from adaptiveness, whereas the momentary union-related stressors do not. It is clear, however, that further research is needed to assess this theory.

As hypothesized, the more strikers expressed cynicism toward the city, the more they also expressed cynicism toward the union. This could be a reflection of the dual allegiance to both management and union that has been found in so many previous studies, e.g., [27-29]. It is also possible that, despite the face validity of each of the items from the cynicism scales, these two measures tapped a general attitude of cynicism rather than a specific attitude toward either organizational body. However, regardless of the focus of employee cynicism, it is clear that this outlook contributes to a negative emotional reaction to the breakdown in labor relations. As well, it is possible that employee age or the duration of a participant's employment with the municipality could influence his/her reported 
level of cynicism toward either the city or the union. Repeated exposure to poor labor relations between management and staff could contribute to the development of employee cynicism. However, no significant correlations between age or duration of employment and either form of cynicism were found.

As expected, and consistent with previous research [14, 20], financial concern did predict greater levels of anger and more negative moods among striking employees. Interestingly, despite having an impact on these affective stress responses, the correlations between financial concern and the cognitive attitudes of city and union cynicism were not significant. Although it might have been argued that financial concern is a source of distress and anxiety that could contribute to a more cynical attitude, it seems that the impact of financial concern was limited to the affective responses of striking employees, and did not extend to their cognitive perceptions.

In terms of changes in attitudinal and emotional reactions over the course of the strike, only financial concern was found to differ. Concern was greatest prior to the strike, when it was unclear how long the dispute would last and how long employees would need to endure a loss of income. Interestingly, although not statistically significant, anger concerning the labor dispute appeared to climax in the weeks following the strike's conclusion and then to decline over the next four months. This reduction in anger suggests that the strike may have had minimal lasting effects on employees. Although close but again not statistically significant, union cynicism also appeared to decline over the three phases of research inquiry. Perhaps the resolution of the dispute provided employees with a reason for increased confidence in, or gratitude for, their union representatives. Unlike cynicism toward the union, city cynicism remained clearly constant over the four-month duration of the study. This differing pattern of change over time for each type of cynicism does support the previously mentioned contention that city cynicism is a more common or everyday cognition, whereas union cynicism may be an infrequent one. Unfortunately, there is no way to determine whether the levels of cynicism reported in the current study were a result of the job action or merely a constant attitude for some employees. This possible longitudinal difference between union and city cynicism also supports the original contention that these two measures are tapping into distinct psychological constructs.

It is possible that a larger sample size would have provided enough power to statistically establish these longitudinal effects, and it is hoped that future research will be able to test some of the contentions put forth as a result of this pilot study. However, it is imperative that the reader recognize that the longitudinal findings concerning financial concern were the only statistically significant longitudinal results in the present study.

Overall, this pilot study identified the Lazarus and Folkman transactional model of stress [8] as a possible framework for understanding the psychosocial impact of labor disputes on employees, and provided some support for this interpretation. This study identified several individual difference factors that 
predict the level of anger and general mood of striking employees, accounting for 58 percent and 50 percent of the variance, respectively. Furthermore, it provided some assessment of the longitudinal changes in attitudes and emotions associated with the job action.

Despite these contributions, this type of field-based pilot study includes some inherent limitations. First, the low number of participants significantly affected the power of the statistical tests and which models could be examined. A larger sample size would have allowed for a more complete assessment of the variables within the transactional model of strike-related stress, as well as the possibility of adaptiveness being a moderator variable between anger and mood, or cynicism being a cognitive response to stress. Second, because this was a field study that took advantage of a sudden situation, there was no opportunity to measure the variables of interest during normal day-to-day business, before the managementunion relations were strained due to an impending strike. Likewise, it was impossible to measure employees' reactions during the job action itself because the strike lasted only sixteen days, ending before the distribution and collection of surveys in a during-strike phase could be completed. The suddenness of the job action also forced the adoption of a snowball sampling technique, which can be problematic.

Future researchers examining these same variables may wish to contact a company and union before contract negotiations begin, as was done by Stagner and Eflal [23]. In this way, researchers can assess these variables during a normal business period, and may be able to facilitate a quick distribution and collection of surveys in a during-strike phase. Moreover, if a researcher contacts a company and union before the tension of an impending strike arises, administrators in each organization may be more likely to assist with the systematic recruitment of participants.

Future research examining other strike-related variables is also necessary, as a multitude of questions remain unanswered. Situational factors, for example, have been mostly ignored in the existing research. How does the duration of a job action influence the reaction to it? How do the specific circumstances of a job action (e.g., strike versus lockout, issues of contention, past union history with the employer) affect employees' emotions and attitudes? Previous research has also not exhausted a review of all possible stress responses to labor disputes. What other psychosocial consequences of a labor conflict might exist (e.g., general anxiety, uncertainty, employee burnout, job dissatisfaction)? To what extent do emotional reactions due to a labor dispute transfer to other environments such as home and social activities, or do these social supports serve to buffer stress? The paucity of research in this area is staggering $[13,38]$, and given the prevalence of labor conflicts in the free market economy, research examining the psychosocial impact of labor disputes could be very beneficial to the health and collective well-being of both organizations and their workforces. 


\section{ACKNOWLEDGMENTS}

I would like to thank the municipality and the union that granted me permission to approach their employees and members, and the participants who volunteered their assistance with this research. I would also like to thank Professor David Wiesenthal, Lisa Fiksenbaum, Mirka Ondrack, and various reviewers for their valuable comments and recommendations for this project.

\section{ENDNOTES}

1. P. Palango, Sudbury on a spree but the strikers dread Christmas, Globe and Mail, p. 7, Dec. 1, 1978.

2. C. Sanders, The strike at Boise Cascade, Industrial Relations Research Report, 3(4), pp. 8-12, 1979.

3. M. Achterkamp and A. Akkerman, Identifying latent conflict in collective bargaining, Rationality and Society, 15, pp. 15-43, 2003.

4. K. Veenstra and A. Haslam, Willingness to participate in industrial protest: Exploring social identification in context, British Journal of Social Psychology, 39, pp. 153-172, 2000 .

5. S. A. Alvi, The impact of strikes on Canadian trade balance, Applied Economics Letters, 8, pp. 389-396, 2001.

6. P. Drinot, Fighting for a closed shop: The 1931 Lima baker workers' strike, Journal of Latin American Studies, 35, pp. 249-278, 2003.

7. J. K. Kramer and G. M. Vasconcellos, The economic effect of strikes on the shareholders of nonstruck competitors, Industrial and Labor Relations Review, 49, pp. 213-222, 1996.

8. R. S. Lazarus and S. Folkman, Stress, appraisal, and coping, New York: Springer, 1984.

9. S. D. Bluen and J. Barling, Psychological stressors associated with industrial relations, in C. L. Cooper and R. Payne (eds.), Causes, coping and consequences of stress at work (pp. 175-205), Toronto: John Wiley \& Sons, Ltd., 1988.

10. M. Girodo, The psychological health and stress of pilots in a labor dispute, Aviation, Space, and Environmental Medicine, 59, pp. 505-510, 1988.

11. A. MacBride, W. Lancee, and S. J. J. Freeman, The psychosocial impact of a labor dispute, Journal of Occupational Psychology, 54, pp. 125-133, 1981.

12. D. Visser and F. Van Staden, The experience of work circumstances and stress: A profile of flight engineers in a labor dispute, Journal of Industrial Psychology, 18, pp. 1-6, 1992.

13. J. Barling and J. Milligan, Some psychological consequences of striking: A six-month, longitudinal study, Journal of Occupational Behaviour, 8, pp. 127-138, 1987.

14. R. H. Vispo and D. Shine, Strike and stress in a maximum security hospital, Psychiatric Quarterly, 57, pp. 111-120, 1985.

15. S. D. Bluen and V. G. Jubiler-Lurie, Some consequences of labor-management negotiations: Laboratory and field studies, Journal of Organizational Behavior, 11, pp. 105-118, 1990.

16. S. D. Bluen and I. Edelstein, Trade union support following an underground explosion, Journal of Organizational Behavior, 14, pp. 473-480, 1993. 
17. J. Barling, S. D. Bluen, and R. Fain, Psychological functioning following an acute disaster, Journal of Applied Psychology, 53, pp. 187-194, 1987.

18. R. J. Burke, Stress, work and professional satisfaction and militancy among Canadian physicians, Journal of Organizational Behavior, 14, pp. 459-472, 1993.

19. R. J. Burke, Stress, satisfaction and militancy among Canadian physicians: A longitudinal investigation, Social Science and Medicine, 43, pp. 517-524, 1996.

20. C. R. Stoner and R. Arora, An investigation of the relationship between selected variables and the psychological health of strike participants, Journal of Occupational Psychology, 60, pp. 61-71, 1987.

21. N. Nicholson and J. Kelly, The psychology of strikes, Journal of Occupational Behaviour, 1, pp. 275-284, 1980.

22. M. E. Gordon, N. Schmitt, and W. G. Schneider, Laboratory research on bargaining and negotiations: An evaluation, Industrial Relations, 23, pp. 218-233, 1984.

23. R. Stagner and B. Eflal, Internal union dynamics during a strike: A quasi-experimental study, Journal of Applied Psychology, 67, pp. 37-44, 1982.

24. E. K. Kelloway, J. Barling, and A. Shah, Industrial relations stress and job satisfaction: Concurrent effects and mediation, Journal of Organizational Behavior, 14, pp. 447-457, 1993.

25. P. M. Kohn, C. O’Brien-Wood, D. I. Pickering, and T. DeCicco, The Personal Functioning Inventory: A reliable and valid measure of adaptiveness in coping, Canadian Journal of Behavioral Science, 35, pp. 111-123, 2003.

26. S. Cohen and T. A. Willis, Stress, social support, and the buffering hypothesis, Psychological Bulletin, 98, pp. 310-357, 1985.

27. L. R. Dean, Union activity and dual loyalty, Industrial and Labor Relations Review, 7, pp. 526-536, 1954.

28. T. V. Purcell, Dual allegiance to company and union-packinghouse workers. A swift-UPWA study in a crisis situation, 1949-1952, Personnel Psychology, 7, pp. 48-58, 1954.

29. C. Fullagar and J. Barling, Predictors and outcomes of different patterns of organizational and union loyalty, Journal of Occupational Psychology, 64, pp. 129-143, 1991.

30. L. A. DeCotiis and T. P. Summers, A path analysis of a model of the antecedents and consequences of organizational commitment, Human Relations, 40, pp. 445-470, 1987.

31. C. Fullagar and J. Barling, A longitudinal test of a model of the antecedents and consequences of union loyalty, Journal of Applied Psychology, 74, pp. 213-227, 1989.

32. R. Martin, D. Watson, and C. K. Wan, A three-factor model of trait anger: Dimensions of affect, behavior, and cognition, Journal of Personality, 68, pp. 869-897, 2000.

33. C. D. Spielberger, State-Trait Anger Expression Inventory, Tampa, Florida: Psychological Assessment Resources, 1988.

34. C. J. Mackay, T. Cox, C. G. Burrows, and A. J. Lazzerini, An inventory for the measurement of self-reported stress and arousal, British Journal of Social and Clinical Psychology, 17, pp. 283-284, 1978.

35. J. A. Eaton, "A social motivation approach to organizational cynicism," unpublished master's thesis, York University, Toronto, Ontario, Canada, 2000. 
36. B. G. Tabachnick and L. S. Fidell, Using multivariate statistics (5th ed.), Needham Heights, Mass.: Allyn \& Bacon, 2001.

37. C. E. Izard, The psychology of emotions, New York: Plenum Press, 1991.

38. J. Barling, Industrial relations - A "blind spot" in the teaching, research and practice of industrial/organizational psychology, Canadian Psychology, 29, pp. 103-108, 1988 .

Direct reprint requests to:

Christine M. Wickens

Department of Psychology

329 Behavioural Sciences Building

York University

4700 Keele Street

Toronto, Ontario M3J 1P3

Canada

e-mail: cwickens@yorku.ca 